\title{
Original axticle
}

\author{
Changes in Serum Electrolytes and Lipid Profile \\ in Diabetes Subjects in Freetown Sierra Leone \\ Oyewole $\mathrm{OI}^{1}{ }^{*}$, Sessie $\mathrm{S}^{2}$, Mansaray $\mathrm{M}^{2}$ And Kamara $\mathrm{B}^{2}$.
}

\begin{abstract}
Background: Measurement of blood electrolytes level and lipid profile usually give good indications of the disease progression in a number of non communicable diseases.

Objective: To investigate the effect of diabetes on electrolyte and lipid status of male and female diabetics in Freetown, Sierra Leone.

Subjects and Methods: Serum concentrations of electrolytes and lipids in one hundred and twenty (120) adult diabetics attending some diagnostic centers in Freetown Sierra Leone were measured and compared with those of one hundred and twenty (120) non-diabetic individuals.

Results: Total cholesterol, LDL-cholesterol, triglycerides and coronary heart disease (CHD) risk ratio in diabetic patients were significantly higher $(\mathrm{P}<0.05)$ than those of non-diabetics. Diabetic subjects also have low HDL-cholesterol compared with the non-diabetics. Analysis of serum electrolytes in diabetic individuals also shows significant reduction in serum $\mathrm{K}^{+}, \mathrm{Na}^{+}$and $\mathrm{HCO}_{3}{ }^{-}$ while $\mathrm{Cl}^{-}$was significantly elevated compared with non-diabetics. There was no significant difference between the sexes in all parameters studied.
\end{abstract}

Conclusion: We conclude that lipid abnormalities and electrolyte imbalance contribute towards complications observed in diabetes.

Keywords: Diabetes Mellitus, electrolytes, lipids, hyperglycaemia,

$\mathrm{D}$ iabetes Mellitus is an endocrine disorder which affects over 100 million people worldwide. It is expected that more than one billion people will suffer from diabetes worldwide by the end of the $21^{\text {st }}$ century 1 . The disease is characterized by inability of the pancreas to produce sufficient amounts of insulin, or failure of the body's cells to respond appropriately to insulin. In people with diabetes, glucose levels build up in the blood and urine, causing excessive urination, thirst, hunger, and problems with fat and protein metabolism ${ }^{2}$.

\footnotetext{
1. Department of Biochemistry,

2-Medical Laboratory Unit,

College of Medicine and Allied Health Sciences, University of Sierra Leone, Freetown.

*Corresponding author

Dr Oyewole O.I. E-mail: ioluoye@yahoo.com. Tel: +23233757782 .
}

The signs and symptoms of diabetes are related to hyperglycemia and other complications relating to lipid production, vascular and microvascular damage, organ damage and slower healing.

Data obtained from the US Census Bureau, International Data Base $^{3}$ revealed that over 350,000 Sierra Leonean mostly adult are diabetic representing about $6 \%$ prevalence of the disease in the population. This high prevalence might be due to high dependence of majority of the population on starchy staple foods with minimal consumption of foods of animal origin.

Electrolytes play an important role in many body processes, such as controlling fluid levels, acid-base balance $(\mathrm{pH})$, nerve conduction, blood clotting and muscle contraction. Electrolyte imbalance resulting from kidney failure, dehydration, fever and vomiting has been suggested as one of the 
contributing factors toward complications observed in diabetes and other endocrine disorders ${ }^{4}$.

Complications of atherosclerosis and lipid abnormalities have been reported to account for the majority of deaths and a disproportionate amount of morbidity in people with diabetes and other conditions characterized by insulin resistance ${ }^{5,6}$. It has been suggested that diabetic patients has 2-4 times higher risk of cardiovascular disease compared to their non-diabetic counterpart ${ }^{7}$.

This study was conducted to investigate electrolyte and lipid imbalance in diabetic subjects in Freetown, Sierra Leone in comparison with non-diabetic individuals. Data obtained in this study will further help in the description and diagnosis of diabetes and also serve as a benchmark for Sierra Leone diabetics in comparison to those in other countries.

\section{METHODOLOGY \\ Selection of Subjects}

One hundred and twenty (120) diabetes subjects (60 males and 60 females) and one hundred and twenty (120) nondiabetics (60 males and 60 females) were used for this study after informed consent. All subjects are adults aged between thirty five (35) and sixty (60). Subjects concerned are those who came for routine blood check up in some diagnostic centers in Freetown Sierra Leone in the period from January to August 2008. None of them were on any medication known to influence electrolyte or lipid metabolism.

\section{Collection of blood samples}

Blood samples were obtained from each subject by venepuncture into a clean sample bottle. The blood was allowed to clot and then centrifuged at 3000rpm for 10 minutes. The serum obtained was pipette into a clean bottle and analysed for glucose immediately while the remaining portion was kept frozen for the rest of the analysis.

\section{Measurement of Serum parameters}

Fasting blood glucose was determined using the glucose oxidase method ${ }^{8}$. Total cholesterol was determined using the chodpap method described by Allain et al. ${ }^{9}$ while serum triglycerides concentration was determined using the method of Fossati and Prencipe $^{10}$. The dextran sulphate $\mathrm{Mg}^{2+}$ method $^{11}$ was employed for estimation of HDL-cholesterol while LDL-cholesterol was determined by the polyvinyl sulphate method $^{12}$. Coronary heart disease risk ratio (CHD risk ratio) was obtained by calculating the ratio of concentrations of total cholesterol to HDL-cholesterol.

Serum sodium and potassium ions were determined by flame photometry using the Jenway Clinical PFP7 Flame Photometer. The method of Schales and Schales ${ }^{13}$ was used to determine chloride ion concentration while serum bicarbonate was determined by back titration method ${ }^{14}$. Assay kits used were obtained from Quimica Clinical Applicada S.A. (QCA), Amposta Spain. All measurements were done using Spectronic 21 digital Spectrophotometer.

\section{Statistical Analysis}

Data obtained were subjected to statistical analysis using Duncan multiple range test following one-way analysis of variance (ANOVA) with the aid of SPSS 10.0 computer software package (SPSS Inc; Chicago, U.S.A). Differences at $\mathrm{P}<0.05$ were considered significant.

\section{Results}

Table 1 show the concentration of serum electrolytes $(\mathrm{Na}+, \mathrm{K}+, \mathrm{Cl}-$ and $\mathrm{HCO} 3-$ ) in diabetics compared with the nondiabetics. There was significant reduction $(\mathrm{P}<0.05)$ in the concentrations of $\mathrm{Na}+, \mathrm{K}+$ and $\mathrm{HCO}_{-}-$in the serum of diabetic individuals compared with the non-diabetics. Serum Cl- was however significantly elevated $(\mathrm{P}<0.05)$ in diabetics. Serum lipid profile in diabetics and their non-diabetic counterpart is shown in Table 2. 
Table 1: Serum electrolytes concentration in diabetic and non diabetic subjects in Freetown Sierra Leone $(\mathrm{mmol} / \mathrm{L})$

\begin{tabular}{|c|c|c|c|c|}
\hline & $\mathrm{Na}^{+}$ & $\mathrm{K}^{+}$ & $\mathrm{Cl}^{-}$ & $\mathrm{HCO}_{3}{ }^{-}$ \\
\hline All diabetics & $125.55 \pm 8.45^{\mathrm{a}}$ & $2.43 \pm 0.49^{\mathrm{a}}$ & $97.81 \pm 6.85^{\mathrm{a}}$ & $21.24 \pm 1.23^{\mathrm{a}}$ \\
\hline All non-diabetics & $138.10 \pm 1.17^{\mathrm{b}}$ & $3.59 \pm 0.86^{\mathrm{b}}$ & $88.06 \pm 7.22^{b}$ & $26.21 \pm 3.40^{b}$ \\
\hline Male diabetics & $124.76 \pm 7.59^{\mathrm{a}}$ & $2.47 \pm 0.72^{\mathrm{a}}$ & $97.10 \pm 6.58^{\mathrm{a}}$ & $21.60 \pm 1.12^{\mathrm{a}}$ \\
\hline Female diabetics & $126.34 \pm 9.10^{\mathrm{a}}$ & $2.39 \pm 0.48^{\mathrm{a}}$ & $98.51 \pm 7.22^{\mathrm{a}}$ & $20.88 \pm 1.25^{\mathrm{a}}$ \\
\hline Male non-diabetics & $138.51 \pm 10.78^{b}$ & $3.56 \pm 0.88^{b}$ & $88.49 \pm 6.88^{b}$ & $25.90 \pm 3.98^{b}$ \\
\hline Female non-diabetics & $137.69 \pm 11.87^{b}$ & $3.61 \pm 0.60^{\mathrm{b}}$ & $87.62 \pm 5.89^{b}$ & $26.52 \pm 3.67^{b}$ \\
\hline
\end{tabular}

Values are Mean \pm SD of all subjects in each group. Values with different alphabetical letter superscripts along a column are significantly different at $\mathrm{P}<0.05$.

Table 2: Serum lipid concentration in diabetic and non diabetic subjects in Freetown Sierra Leone $(\mathrm{mmol} / \mathrm{L})$

\begin{tabular}{l|ccccc} 
& HDL-Chol. & LDL-Chol. & Total Chol. & TAG & CHD riskratio \\
\hline All diabetics & $1.15 \pm 0.07^{\mathrm{a}}$ & $2.18 \pm 0.43^{\mathrm{a}}$ & $3.86 \pm 1.22^{\mathrm{a}}$ & $3.10 \pm 0.94^{\mathrm{a}}$ & $3.36 \pm 0.11^{\mathrm{a}}$ \\
All non-diabetics & $1.76 \pm 0.12^{\mathrm{b}}$ & $1.14 \pm 0.08^{\mathrm{b}}$ & $2.98 \pm 0.45^{\mathrm{b}}$ & $1.98 \pm 0.78^{\mathrm{b}}$ & $1.69 \pm 0.06^{\mathrm{b}}$ \\
Male diabetics & $1.10 \pm 0.08^{\mathrm{a}}$ & $2.15 \pm 0.35^{\mathrm{a}}$ & $3.77 \pm 1.20^{\mathrm{a}}$ & $2.97 \pm 1.00^{\mathrm{a}}$ & $3.43 \pm 0.12^{\mathrm{a}}$ \\
Female diabetics & $1.20 \pm 0.05^{\mathrm{a}}$ & $2.21 \pm 0.41^{\mathrm{a}}$ & $3.95 \pm 1.16^{\mathrm{a}}$ & $3.23 \pm 0.94^{\mathrm{a}}$ & $3.29 \pm 0.17^{\mathrm{a}}$ \\
Male non-diabetics & $1.68 \pm 0.16^{\mathrm{b}}$ & $1.09 \pm 0.07^{\mathrm{b}}$ & $2.81 \pm 0.52^{\mathrm{b}}$ & $1.90 \pm 0.69^{\mathrm{b}}$ & $1.67 \pm 0.05^{\mathrm{b}}$ \\
Female non-diabetics & $1.84 \pm 0.18^{\mathrm{b}}$ & $1.19 \pm 0.09^{\mathrm{b}}$ & $3.15 \pm 0.65^{\mathrm{b}}$ & $2.06 \pm 0.75^{\mathrm{b}}$ & $1.71 \pm 0.05^{\mathrm{b}}$
\end{tabular}

Values are Mean \pm SD of all subjects in each group. Values with different alphabetical letter superscripts along a column are significantly different at $\mathrm{P}<0.05$. 
It can be observed that total cholesterol, LDLcholesterol, triglycerides and coronary heart disease (CHD) risk ratio in diabetic subjects were significantly higher $(\mathrm{P}<0.05)$ than those of non-diabetics. Diabetic subjects however have significantly low HDL-cholesterol compared with the non-diabetics. Statistical analysis showed no significant sex differences in all parameters measured in both diabetics and the non-diabetics.

\section{Discussion}

The observed reduction in serum $\mathrm{Na}^{+}$ and $\mathrm{K}^{+}$in diabetic subjects might be a result of electrolyte loss which arises due to dehydration or a result of kidney dysfunction caused by diabetes ${ }^{4}$. As the body tries to flush out excess glucose due to hyperglycemia, water is also flushed out continuously through the kidney tubules. This water loss is accompanied by $\mathrm{Na}^{+}$and $\mathrm{K}^{+}$ loss. Such rapid loss of sodium and potassium, if continued could soon bring about depletion of base in the body sufficient to cause dehydration of the tissues which may result in death ${ }^{15}$. Sodium and potassium depletion is a common feature of essential hypertension and type II diabetes ${ }^{16}$.

The significant elevation of serum chloride and reduction in $\mathrm{HCO}_{3}{ }^{-}$in diabetic subjects might be due to diabetic ketoacidosis $^{2}$. The low serum insulin levels in diabetics signal the body to produce more glucose via gluconeogenesis, glycogenolysis and ketogenesis which results in excess production of ketone bodies. In this condition, ketone bodies in the blood are elevated and blood bicarbonate may fall to near zero, with resultant severe acidosis ${ }^{17}$. The reduction in blood $\mathrm{pH}$ caused by ketoacidosis might result in acid base imbalance which may lead to elevation of chloride by the system in order to compensate for the anion $\operatorname{loss}^{15}$. This electrolytes imbalance might also occur due to inhibition of the rennin-angiotensinaldosterone system, which plays a key role in the regulation of fluid and electrolyte balance. This enzyme system has been reported to be affected in many endocrine and cardiovascular diseases particularly diabetes ${ }^{16}$.

The observed increase in total cholesterol, LDL-cholesterol, triglycerides and CHD risk ratio accompanied with reduced HDL-cholesterol in diabetics shows lipid abnormalities and is synonymous with increased risk of atherosclerosis ${ }^{18,}{ }^{19}$. This abnormal lipid profile in diabetics might have resulted from insulin deficiency which plays major roles in intermediary metabolism ${ }^{20,21}$. In type- 2 diabetic, patient's abnormalities in lipoproteins are presumed to be responsible for the increased risk of macrovascular disease because each lipid and lipoprotein fraction is affected by insulin resistance and hyperglycaemia ${ }^{22}$.

\section{Conclusion}

This study provided data to show that diabetics subjects in Freetown Sierra Leone have electrolytes imbalance characterized with depletion in sodium and potassium ions accompanied with elevation of chloride ion compared with their non diabetic counterparts. However there is no significant difference in values obtained for the two sexes both for diabetics and non-diabetics. This study shows that electrolyte imbalance is one of the contributing factors toward complications observed in diabetes. Results obtained in this study will further assist Clinicians in the use of electrolytes and lipids laboratory data for the diagnosis of diabetes cases in Sierra Leone.

\section{References}

1. Amos AF, McCarty DJ, Zimmet P. The rising global burden of diabetes and its complications: estimates and projections to the year 2010. Diabet. Med 1997; 14 (Suppl. 5):S7-S85.

2. Cowie CC, Harris MI. Physical and metabolic characteristics of persons with diabetes. Diabetes in America. $2^{\text {nd }}$ ed. National Institutes of Health 1995; 117-164.

3. US Census Bureau, International Data Base. Statistics by country for diabetes. 2004; 1-11.

4. Rao GM. Serum electrolytes and osmolality in diabetes mellitus. Indian J Med Sci 1992; 46 (10):301303. 
5. Krolewski S, Czyzyk A, Janeczko D et al. Mortality from Cardiovascular Diseases among diabetics. Diabetologia 1977; 13:345-350.

6. Folsom AR, Szklo M, Stevens Jet al. A prospective study of coronary heart disease in relation to fasting insulin, glucose, and diabetes. Diabetes Care 1997; 20:935-942.

7. George P, Ludvik B. Lipids and Diabetes J. Clin. Basic Cardiol 2000; 3:159162

8. Raabo E, Terkildsen TC. On the enzymatic determination of blood glucose. Scand. J. Clin. Lab. Invest. 1960; 12:402-407.

9. Allain CC, Poon LS, Chan CSG et al. Monoreagent enzymatic cholesterol. Clin. Chem. 1974; 20:470-475.

10. Fossati P, Prencipe L. Serum triglycerides determination colorimetrically with an enzyme that produces hydrogen peroxide. Clin. Chem. 1982; 28(10):2077-2080.

11. Benzie I. High density lipoprotein-cholesterol. Med. Lab. Sci. 1979; 36:280-291.

12. Assmann G, Jabs HU, Kohnert U et al. Low density lipoprotein-cholesterol method. Clin. Chem. Acta 1984; 140:77-83.

13. Schales O, Schales SS. A simple and accurate method for determination of chlorides in biological fluids. J. Biol. Chem. 1941; 140:79-82

14. Tietz NW, Pruden EL, Siggaard-Andersen O. In: Tietz textbook of Clinical Chemistry (Burtis C.A. and
Ashwell E.R. Eds.) W.B Saunders Company London. 1994; 1354-1374.

15. Leonard IK, John M. Physiology and pathophysiology of body water and electrolytes. In: Kaplan and Pesce (Eds.), Clinical Chemistry: Theory, analysis and correlation. The C.V. Mosby Co. St Louis. 1989; Pp 313-331.

16. Van Style DD, Serdroy J. Studies on diabetes and electrolyte equilibrium in blood. J Biol Chem 1928; 18: 20-26.

17. Haffner SM, Miettinen H. Insulin resistance implications for type II diabetes mellitus and coronary heart disease. Am J Med 1997; 103:152-162.

18. Frohlich JJ, Pritchard PH. The clinical significance of serum high density lipoproteins. Clin Biochem 1989; 22(6):417-423.

19. Grundy SM. Small LDL, atherogenic dyslipidemia and the metabolic syndrome. Circulation 1997; 97:1029-1036.

20. Dun FL. Hyperlipidemia and diabetes. The Med Clins North America 1982; 66(16):1347-1360.

21. National Institute of Health (NIH), USA. Triglyceride, HDL-cholesterol and coronary heart disease. JAMA 1993; 269:505-510.

22 .Winocour PH, Durrington PN, Bhatnagar D et al. Abnormalities of VLDL, IDL, and LDL characterize insulin-dependent diabetes mellitus. Arterioscler Thromb 1992; 12:920-928. 